\title{
Reversibility of the Pulmonary Function Based on the Partial Flow-volume Curve Predicts the Efficacy of Bronchodilator Therapy for Treating Chronic Cough
}

\author{
Yusuke Nakade ${ }^{1}$, Masaki Fujimura ${ }^{2}$, Noriyuki Ohkura ${ }^{2}$, Masako Nakata ${ }^{1}$, Yuko Nanbu ${ }^{1}$, \\ Hiroyasu Oe ${ }^{1}$, Hiroshi Horita ${ }^{1}$, Yoshio Sakai ${ }^{1}$ and Takashi Wada ${ }^{1}$
}

\begin{abstract}
Objective Partial expiratory flow-volume curves have the potential to detect mild bronchoconstriction because they are not affected by the modulatory effects of deep inspiration. The aim of this study was to investigate the relationship between the efficacy of bronchodilator therapy (BDT) in treating the cough and to assess the increase in the expiratory flow of the partial flow-volume curve at $40 \%$ above the residual volume level $\left(\mathrm{PEF}_{40}\right)$ caused by treatment with a short-acting beta-2 agonist (SABA) in patients with chronic nonproductive cough.

Methods We measured the reversibility of $\mathrm{PEF}_{40}$ caused by a SABA in 42 patients with chronic nonproductive cough at visit 1 (day 0 ). The patients received BDT for six days. The visual analogue scale (VAS) was used to assess the efficacy of BDT in treating coughing at visit 2 (day 7) $(0 \mathrm{~mm}$, 'no cough;' $100 \mathrm{~mm}$, 'no change in coughing').

Results Reversibility of the $\mathrm{PEF}_{40}$ was correlated $(\mathrm{r}=0.690, \mathrm{p}<0.001)$ with the VAS score determined at visit 2 and was higher in the patients with cough variant asthma (CVA) $(44.9 \pm 18.3 \%)$ than in those with atopic cough $(13.4 \pm 10.4 \%)(\mathrm{p}<0.01)$.

Conclusion Reversibility of the $\mathrm{PEF}_{40}$ predicted the efficacy of BDT in patients with chronic nonproductive cough and helped to identify patients with CVA.
\end{abstract}

Key words: atopic cough, chronic nonproductive cough, cough variant asthma, pulmonary function tests

(Intern Med 52: 2017-2023, 2013)

(DOI: 10.2169/internalmedicine.52.8604)

\section{Introduction}

Cough variant asthma (CVA) is one of the major causes of chronic nonproductive cough in Japan (1). Corrao et al. reported CVA to be a subtype of asthma in 1979 (2). CVA is very similar to typical asthma; however, the only characteristic phenotype of CVA is chronic nonproductive cough (2). The guidelines for the management of cough $(3,4)$ recommend that the diagnosis be made based on therapeutic efficacy. The placebo effect, natural improvements and difficult to treat cases present major problems in making a diagnosis based on therapeutic efficacy. Therefore, there is an urgent need to investigate the clinical features of
CVA that can be applied to making a diagnosis based on the pathophysiological condition of the patient. We recently demonstrated that a heightened cough response to bronchoconstriction is a fundamental feature of CVA (5).

We took note of the characteristics of partial and full flow-volume curves reported by Fish et al. $(6,7)$, which have the potential to detect mild bronchial smooth muscle contractions because they are not affected by the modulatory effects of deep inspiration (bronchodilation and bronchoconstriction when bronchospasm and bronchodilation are induced, respectively) $(6,7)$. Therefore, we hypothesized that the reversibility of the partial flow-volume curve at $40 \%$ above the residual volume level $\left(\mathrm{PEF}_{40}\right)$, which is assumed not to be affected by the modulatory effects of deep inspira- 
Table 1. Characteristics of the Subjects

\begin{tabular}{|c|c|c|c|c|}
\hline \multicolumn{5}{|c|}{ Patients with chronic nonproductive cough } \\
\hline & Total & CVA & $\mathrm{AC}$ & $\mathrm{p}$ value \\
\hline Number: & 42 & 30 & 12 & \\
\hline Gender ( $\%$ of Male): & $43 \%$ & $43 \%$ & $42 \%$ & N.S. \\
\hline Age (years): & $46.1 \pm 24.3$ & $42.2 \pm 15.6$ & $55.8 \pm 37.5$ & N.S. \\
\hline Height $(\mathrm{cm})$ : & $161.2 \pm 19.0$ & $164.3 \pm 8.4$ & $153.5 \pm 32.7$ & N.S. \\
\hline Body weight $(\mathrm{kg})$ : & $58.4 \pm 13.5$ & $60.7 \pm 12.0$ & $53.2 \pm 15.8$ & N.S. \\
\hline Exhaled nitric oxide (ppb): & $29.5 \pm 35.5$ & $40.0 \pm 41.0$ & $11.2 \pm 5.2$ & $<0.001$ \\
\hline \multicolumn{5}{|l|}{ Pulmonary function } \\
\hline PEF40 (L): & $3.0 \pm 1.3$ & $2.7 \pm 1.0$ & $3.7 \pm 1.7$ & 0.07 \\
\hline FVC (L): & $3.8 \pm 1.0$ & $3.9 \pm 1.0$ & $3.8 \pm 1.1$ & N.S. \\
\hline FVC (\% pred.): & $116.6 \pm 15.0$ & $117.2 \pm 1.6$ & $115.0 \pm 11.2$ & N.S. \\
\hline $\mathrm{FEV}_{1}(\mathrm{~L}):$ & $3.2 \pm 0.9$ & $3.3 \pm 1.1$ & $3.3 \pm 1.1$ & N.S. \\
\hline $\mathrm{FEV}_{1}(\%$ pred. $):$ & $109.5 \pm 14.7$ & $108.5 \pm 16.1$ & $112.2 \pm 10.8$ & N.S. \\
\hline $\mathrm{FEV}_{1} / \mathrm{FVC}$ ratio $(\%)$ : & $84.0 \pm 8.2$ & $82.8 \pm 8.3$ & $86.9 \pm 7.5$ & N.S. \\
\hline MMF (L/sec): & $3.2 \pm 1.3$ & $3.1 \pm 1.2$ & $3.6 \pm 1.6$ & N.S. \\
\hline MMF (\%pred.): & $82.0 \pm 21.8$ & $78.9 \pm 22.2$ & $89.7 \pm 19.8$ & N.S. \\
\hline V50 (L/sec): & $3.8 \pm 1.4$ & $3.7 \pm 1.3$ & $4.2 \pm 1.7$ & N.S. \\
\hline V50 (\%pred.): & $78.3 \pm 20.4$ & $75.5 \pm 20.0$ & $85.1 \pm 20.7$ & N.S. \\
\hline V25 (L/sec): & $1.5 \pm 0.9$ & $1.4 \pm 0.8$ & $1.8 \pm 1.1$ & N.S. \\
\hline V25 (\%pred.): & $58.8 \pm 23.6$ & $55.4 \pm 22.1$ & $67.6 \pm 25.9$ & N.S. \\
\hline Reversibility of PEF40 (\%): & $34.8 \pm 22.4$ & $43.4 \pm 20.0$ & $13.4 \pm 10.8$ & $<0.001$ \\
\hline Reversibility of FVC (\%): & $0.7 \pm 2.5$ & $0.5 \pm 2.6$ & $0.8 \pm 2.0$ & N.S. \\
\hline Reversibility of $\mathrm{FEV}_{1}(\%)$ : & $2.8 \pm 2.5$ & $3.0 \pm 2.7$ & $2.5 \pm 1.9$ & N.S. \\
\hline
\end{tabular}

tion, can predict the efficacy of bronchodilator therapy (BDT) in treating chronic nonproductive cough. The aim of this study was to investigate the relationship between the efficacy of BDT and markers of pulmonary function tests (PFTs) [reversibility of the $\mathrm{PEF}_{40}$, and FEV1 by a shortacting beta-2 agonist (SABA)] and physiological airway properties [sensitivity of the cough to capsaicin (C5) and the methacholine provocation concentration producing a $20 \%$ decrease $\left(\mathrm{PC}_{20}\right)$ in $\left.\mathrm{FEV} 1\right]$ in patients with chronic nonproductive cough.

\section{Materials and Methods}

\section{Patients}

Forty-two patients with chronic nonproductive cough gave their informed consent to participate in this study. The characteristics of the patients are shown in Table 1. This study was performed at Kanazawa University Hospital between February 2011 and February 2012 and was approved by the ethics committee of Kanazawa University Hospital (Approval No.717) and conducted in accordance with the Declaration of Helsinki.

\section{Spirometric measurements}

The spirometric measurements were obtained according to international criteria (8). The pulmonary function test system CHESTAC-9800 (CHEST M.I. Inc., Tokyo, Japan) was used to measure the $\mathrm{PEF}_{40}$, forced vital capacity (FVC) and $\mathrm{FEV}_{1}$. The maximal expiratory flow rates at $50 \%$ and $25 \%$ of the forced vital capacity (V50 and V25) were obtained from the flow-volume curves. The MMF (maximal mid-expiratory flow) is the average of the expiratory flow at $25-75 \%$ of the forced vital capacity. The patients were coached on how to perform the standard forced expiratory maneuvers. Three technically acceptable blows were recorded, and the best values were retained.

\section{Partial and full flow-volume curves}

Examples of partial and full flow-volume curves are shown in Fig. 1a. The partial and full flow-volume curves were measured using the modified method of Fish et al. $(6,7)$. The partial curves were created based on the endtidal inspiration: upon reaching the residual volume level, patient inspired to the total lung capacity level (deep inspiration) and performed the maneuver to achieve a full curve. In detail, the $\mathrm{PEF}_{40}$ represented the expiratory flow at $40 \%$ above the residual volume level from the full FVC, and the volume level was used as the reference volume level to determine the isovolume flow from the partial curve.

\section{Methacholine inhalation challenge}

Methacholine chloride was dissolved in phosphatebuffered saline solution (PBS) to concentrations of 0.04 , $0.08,0.16,0.31,0.63,1.25,2.5,5,10,20,40,80$ and 160 $\mathrm{mg} / \mathrm{mL}$. PBS and MCh were inhaled via a nebulizer (DeVilbiss 646; DeVilbiss HealthCare, Somerset, PA, USA) operated by compressed air at $5 \mathrm{~L} / \mathrm{min}$. The maneuvers to achieve partial and full flow-volume curves were performed using a computerized spirometer (CHESTAC-9800; CHEST, Tokyo, Japan) before the challenge. PBS was then inhaled for two minutes and the partial and full flow-volume curves 

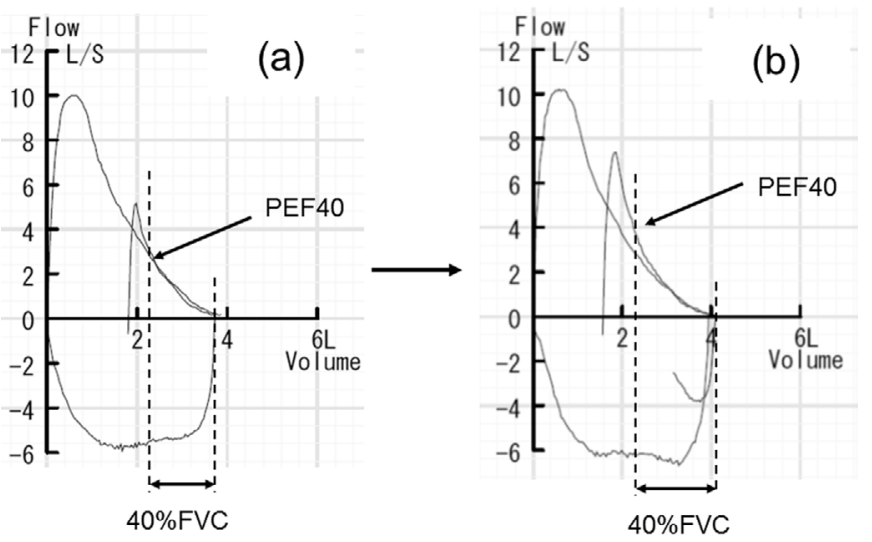

Figure 1. Examples of partial and full expiratory flow-volume curves pre- (a) and post- (b) inhalation following the administration of a short-acting beta-2 agonist (SABA). The reversibility of the $\mathrm{PEF}_{40}$ is given by the reversibility of $\mathrm{PEF}_{40}=$ [(post $\mathrm{PEF}_{40}$-pre $\left.\mathrm{PEF}_{40}\right) /$ pre $\left.\mathrm{PEF}_{40}\right] \times 100(\%) . \mathrm{PEF}_{40}$, expiratory flow of the partial flow-volume curve at $40 \%$ above the residual volume level.

were again measured. After confirming that the PBS inhalation caused neither bronchoconstriction nor coughing, $\mathrm{MCh}$ was then inhaled for two minutes using tidal breathing with the patient wearing a nose clip, followed immediately by obtaining further measurements of the partial and full flowvolume curves. Increasing concentrations of MCh were inhaled until a decrease of $20 \%$ in the FEV1 (PC20-FEV1) from the post-PBS value was achieved. Bronchial hyperresponsiveness was defined as a PC20 of $<10 \mathrm{mg} / \mathrm{mL}$ (7).

\section{Assessment of sensitivity of the cough to capsaicin}

Measurement of the cough threshold for inhaled capsaicin was carried out using the method reported previously. Capsaicin (30.5 mg) was dissolved in Tween $80(1 \mathrm{~mL})$ and ethanol $(1 \mathrm{~mL})$ and then dissolved in physiological saline $(8$ $\mathrm{mL}$ ) to provide a stock solution of $1 \times 10-2 \mathrm{M}$, which was stored at $-20^{\circ} \mathrm{C}$. The solution was diluted with physiological saline to create solutions of $0.49,0.98,1.95,3.9,7.8,15.6$, $31.2,62.5,125,250,500$ and 1,000 $\mu \mathrm{M}$. Each subject inhaled a control solution of physiological saline followed by progressively increasing concentrations of the capsaicin solution. The solutions were inhaled for 15 seconds every 60 seconds using tidal mouth breathing wearing a nose clip with a Bennett Twin nebulizer (3012-60 cc; Puritan-Bennett Co., Carlsbad. CA, USA) operated by compressed air at 5 L-min-1. Increasing concentrations were inhaled until five or more coughs were elicited. The output of the nebulizer was $0.21 \mathrm{~mL} \cdot \mathrm{min}-1$. It has been reported that the aerodynamic mass median diameter (MMD) of the particle is $3.60 \mu \mathrm{m}$, with a geometric standard deviation of 3.47 (9). The number of capsaicin-induced coughs was counted by two medical technicians in the Pulmonary Function Laboratory of Kanazawa University. The cough threshold was defined as the lowest concentration of capsaicin that elicited five or more coughs. Cough hypersensitivity was defined as a capsaicin cough threshold of $<3.9 \mu \mathrm{M}(10)$.

\section{Diagnostic criteria}

The diagnosis of CVA was made according to the following criteria: (1) isolated chronic nonproductive coughing lasting for more than eight weeks; (2) the absence of a history of wheezing or dyspnea, and no adventitious lung sounds on a physical examination; (3) relief of coughing with bronchodilator therapy; and (4) an FEV1, forced vital capacity (FVC) and FEV1_FVC ratio within the normal limits. The diagnosis of atopic cough (AC) was made according to the following criteria: (1) nonproductive coughing lasting more than eight weeks without wheezing or dyspnea; (2) coughing resistant to bronchodilator therapy (oral clenbuterol at a dose of $40 \mu \mathrm{g}$ /day plus inhaled salbutamol at a dose of $200 \mu \mathrm{g}$ at bedtime and on demand); (3) the presence of one or more findings indicative of an atopic constitution, including a history and or complications of allergic disease, excluding asthma, peripheral blood eosinophilia $(>5 \%$ or $>$ 400 cells $/ \mu \mathrm{L})$, an elevated total serum $\operatorname{IgE}$ level (>150 IU $\mathrm{mL}$ ), positive findings for $\mathrm{IgE}$ antibodies specific to aeroallergens and/or induced sputum eosinophilia (>2.5\%); (4) resolution of cough attacks with histamine $\mathrm{H} 1$ antagonists and/or inhaled and/or oral corticosteroid therapy.

\section{Assessment of the efficacy of cough treatment}

The efficacy of the cough treatment was assessed using a subjective cough symptom scale (cough scale). During the 1-week observation period and the following 2-week treatment period, all patients recorded their cough scores in a cough diary. Coughing was scored on a scale from 0 to 10 points, based on the severity and frequency of the cough for 24 hours at the first visit, after the 1-week observation period and after the 2-week treatment period. A score of 0 indicated "no cough," whereas a score of 10 denoted "a cough as bad as that observed at the first visit". Based on the cough diaries, the average score of three days (days 5, 6 and 7 from the first visit) was used as the cough scale score for week 1 and that of three days (days 19, 20 and 21 from the first visit) was used as the cough scale score for week 3 . The efficacy of bronchodilator therapy with respect to making a diagnosis of CVA was evaluated based on the changes in the cough scale score before and after treatment ( $\Delta$ cough scale): $10-8$ points was regarded as excellent, $7-5$ points was regarded as good, 4-3 points was regarded as fairly good and 2-0 points was regarded as unsatisfactory. When the $\Delta$ cough scale was 3 or more, the bronchodilator therapy was judged to be effective.

\section{Study design}

The study design is shown in Fig. 2. We used partial and full flow-volume curves to measure bronchial reversibility following treatment with an SABA in each patient at visit 1 (day 0 ). We also measured the $\mathrm{C} 5$ and exhaled nitric oxide levels at visit 1 .

The patients received BDT for six days. The visual ana- 


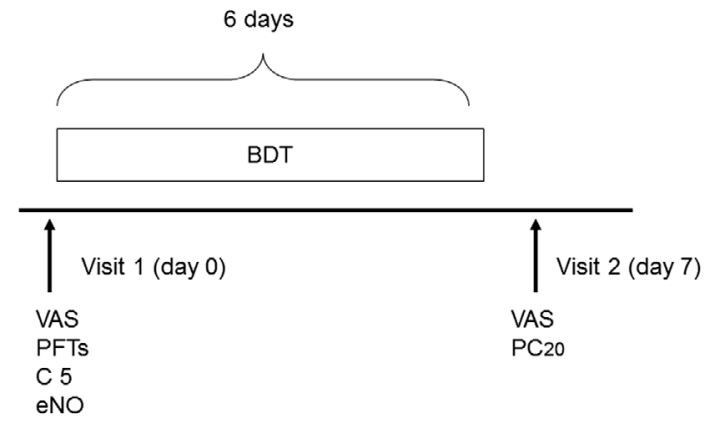

Figure 2. Study design. C5: cough sensitivity to capsaicin, eNO: exhaled nitric oxide, BDT: bronchodilator therapy, VAS: visual analogue scale

logue scale (VAS) was used to evaluate the efficacy of BDT (oral clenbuterol at a dose of $40 \mu \mathrm{g} /$ day + inhaled salbutamol sulphate at a dose of $200 \mu \mathrm{g}$ on demand) in treating the cough at visit 2 (day 7) (0 mm indicated 'no cough;' 100 $\mathrm{mm}$ denoted 'no change in coughing'). We also measured the $20 \%$ fall in the $\mathrm{FEV}_{1}\left(\mathrm{PC}_{20}\right)$ at visit 2. The patients stopped receiving BDT 24 hours or more before the measurement of $\mathrm{PC}_{20}$ to avoid the influence of $\mathrm{BDT}$ on $\mathrm{PC}_{20}$.

The reversibility of the $\mathrm{PEF}_{40}$ was calculated based on the reversibility of the $\mathrm{PEF}_{40}=\left[\left(\right.\right.$ post $\mathrm{PEF}_{40}$-pre $\left.\mathrm{PEF}_{40}\right) /$ pre $\left.\mathrm{PEF}_{40}\right] \times 100(\%)$.

\section{Data analysis}

The SPSS II software package for Windows (SPSS, Chicago, IL, USA) was used for all statistical analyses. A single linear regression analysis was used to examine the relationship between the efficacy of BDT in treating the cough (the VAS score at the 2nd visit) and the reversibility of the $\mathrm{PEF}_{40}, \mathrm{FEV} 1, \mathrm{C} 5$ and $\mathrm{PC}_{20}$. The Mann-Whitney U-test was used to compare the reversibility of the $\mathrm{PEF}_{40}$ between the patients with CVA and AC. Receiver operating characteristic (ROC) curves (11) were used to examine the predictive performance of the reversibility of the $\mathrm{PEF}_{40}$ with respect to the efficacy of BDT in treating the cough, which helped to make the differential diagnosis between CVA and AC. The ROC curves plot the sensitivity (true positives) on the $y$-axis against 1 - the specificity (false positives) on the $\mathrm{x}$-axis, considering each value as a possible cutoff value. The discriminant efficacy of $\mathrm{PEF}_{40}$ was assessed according to the area under the curve (AUC). Results of $\mathrm{p}<0.05$ were considered to be statistically significant.

\section{Results}

\section{Participant selection and baseline characteristics}

Fifty-six patients whose sole or predominant respiratory symptom was chronic coughing persisting for more than eight weeks without wheezing or dyspnea were enrolled in this study. Fourteen of the 56 patients were excluded due to a lack of evaluation of BDT or $\mathrm{PEF}_{40}$ (six cases of full- blown asthma, one case of pertussis, one case of undefined etiology, four cases of poor performance of $\mathrm{PEF}_{40}$ measurement and two cases of dropout from the protocol). Following completion of the diagnostic procedures, including therapeutic diagnosis, 30 and 12 patients were diagnosed to have CVA and AC, respectively.

Table 1 shows the characteristics of the subjects. The level of exhaled nitric oxide in the CVA patients was significantly higher than that observed in the AC patients $(40.0 \pm$ 41.0 vs. $11.2 \pm 5.2, \mathrm{p}<0.01)$. The $\mathrm{PEF}_{40}$ values of the CVA patients tended to be lower than those of the AC patients $(2.7 \pm 1.0$ vs. $3.7 \pm 1.7, \mathrm{p}=0.07)$. Reversibility of the $\mathrm{PEF}_{40}$ in the CVA patients was significantly higher than that observed in the AC patients $(43.4 \pm 20.0$ vs. $13.4 \pm 10.8, \mathrm{p}<0.001)$ (Fig. 4, Scatter plot). Regarding the other parameters, no significant differences were found between the patients with CVA and the patients with AC.

\section{Associations between the VAS scores and parame- ters of the PFTs}

The correlations between the VAS scores and the parameters of the PFTs in the patients with chronic nonproductive cough are shown in Fig. 3. Reversibility of the $\mathrm{PEF}_{40}(\mathrm{r}=$ $-0.690, \mathrm{p}<0.001), \mathrm{C} 5(\mathrm{r}=-0.571, \mathrm{p}<0.01), \mathrm{V} 50(\mathrm{r}=-0.380, \mathrm{p}<$ $0.05), \mathrm{V} 25(\mathrm{r}=-0.346, \mathrm{p}<0.05)$ and MMF $(\mathrm{r}=-0.340, \mathrm{p}<0.05)$ was significantly correlated with the efficacy of BDT in treating the cough (the VAS score at the 2nd visit). Reversibility of the $\mathrm{FEV}_{1}$ and $\mathrm{PC}_{20}$ was not correlated with the VAS scores $(p>0.05)$.

\section{Discrimination between the CVA patients and the AC patients using ROC curves}

The ROC curves were used to discriminate between the CVA patients and the AC patients. The ROC curve for the performance of reversibility of the $\mathrm{PEF}_{40}$ in predicting the efficacy of BDT in treating the cough is shown in Table 2 and Fig. 5. The AUC was 0.851 when the cutoff value of $\mathrm{PEF}_{40}$ was $20 \%$ (Table 2).

\section{Discussion}

The two major causes of chronic nonproductive cough in Japan are CVA and AC (1). Although both conditions cause eosinophilic airway inflammation, each exhibits different clinical features. The clinical features of CVA include mild bronchial hyperresponsiveness (BHR) (2), a heightened bronchial smooth muscle tone (12) and a normal C5 value (12). CVA responds to treatment with BDT (2). On the other hand, the clinical features of AC include a low $\mathrm{C} 5$ value (12) and normal BHR (12-14). AC does not respond to treatment with BDT, although it does respond to treatment with histamine $\mathrm{H} 1$-antagonists and corticosteroids $(13,14)$.

Patients with chronic nonproductive cough sometimes do not present with characteristic examination findings; therefore, it is difficult to diagnose the cause of chronic coughing 

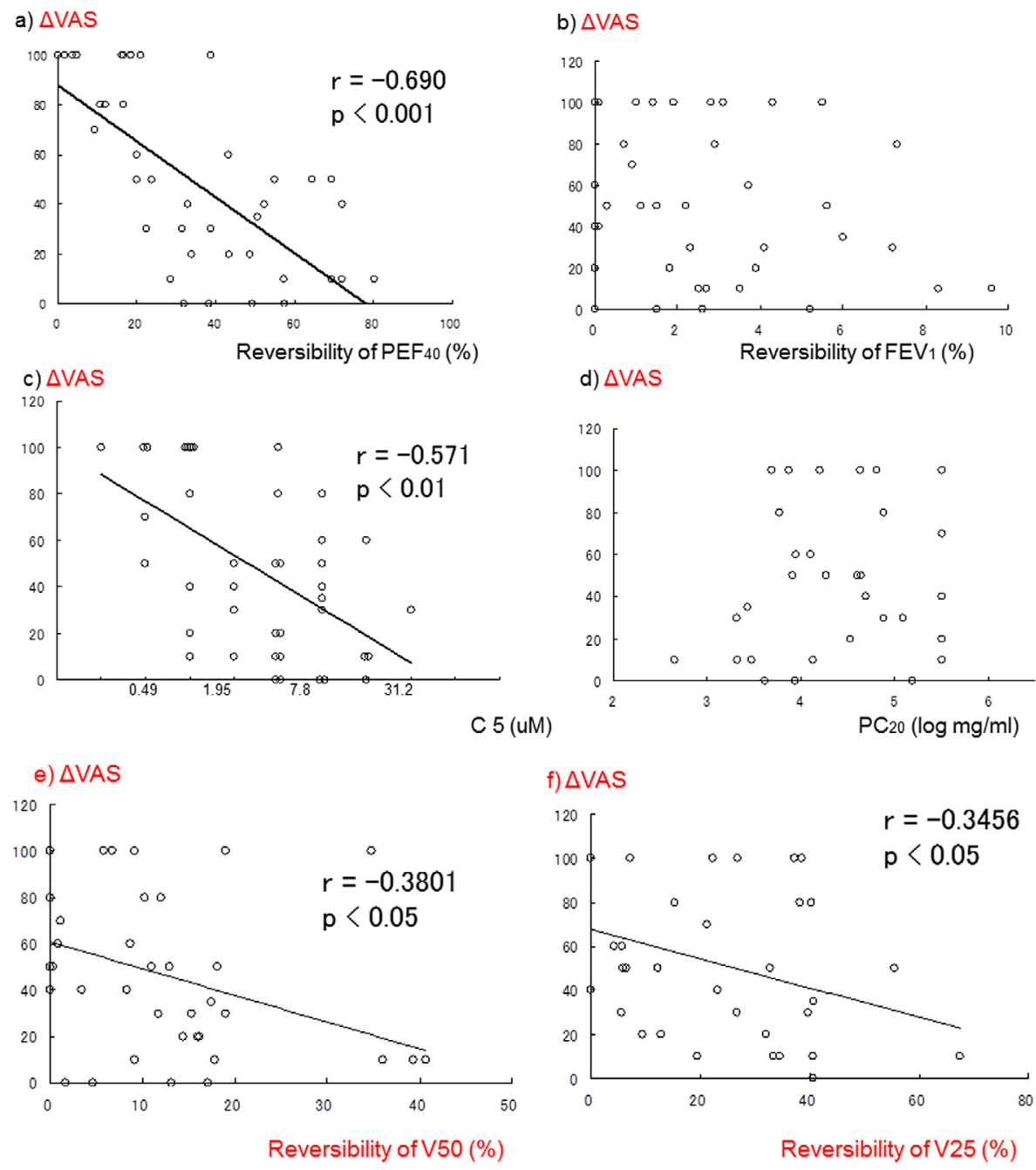

g) $\triangle$ VAS

$\mathrm{n}=42$

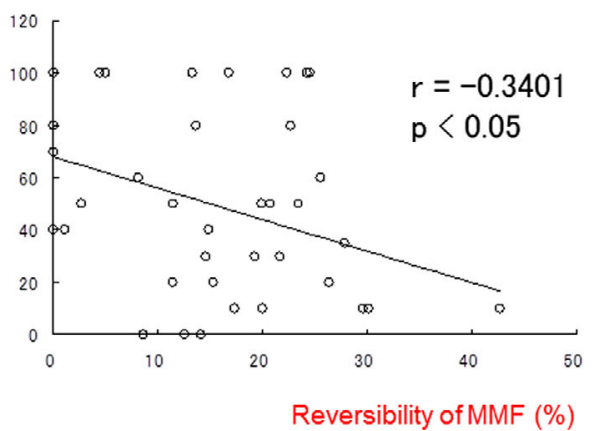

Figure 3. Correlation between the visual analog scale (VAS) at the 2 nd visit and the reversibility of the expiratory flow of the partial flow-volume curve at $40 \%$ above residual volume level $\left(\mathbf{P E F}_{40}\right)$ (a), forced expiratory volume in 1 second $\left(\mathrm{FEV}_{1}\right)(\mathrm{b})$, cough sensitivity to capsaicin (C5) (c), the methacholine provocation concentration producing a $20 \%$ fall $\left(\mathrm{PC}_{20}\right)$ in $\mathrm{FEV}_{1}(\mathrm{~d})$, the maximal expiratory flow rates at $50 \%$ and at $25 \%$ of the forced vital capacity (V50, and V25, (e, f) and MMF (maximal mid-expiratory flow) which is the average of expiratory flow $25 \%-75 \%$ of the forced vital capacity (g).

based on the findings of examinations alone. The guidelines for the management of cough $(3,4)$ recommend that a diagnosis be made based on therapeutic efficacy. In this study, we investigated the clinical features of chronic nonproductive cough that could be applied when making a diagnosis based on the patient's pathophysiological condition. In particular, the aim of this study was to investigate the relation- ship between the efficacy of BDT in treating the cough (the VAS score at the 2nd visit) and markers of PFTs (reversibility of the $\mathrm{PEF}_{40}, \mathrm{FEV}_{1}, \mathrm{C} 5$ and $\mathrm{PC}_{20}$ ) in patients with chronic nonproductive cough. Fig. 3a shows that the VAS score at the 2nd visit was most significantly correlated with reversibility of the $\mathrm{PEF}_{40}$. The $\mathrm{PEF}_{40}$ can be used to detect mild bronchial smooth muscle contractions because it is not af- 


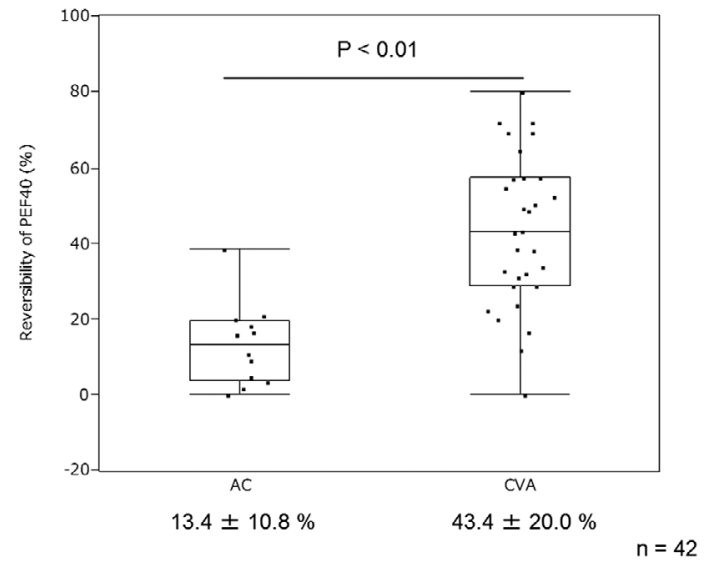

Figure 4. Comparison of the reversibility of the expiratory flow of the partial flow-volume curve at $40 \%$ above the residual volume level $\left(\mathrm{PEF}_{40}\right)$ between the patients with chronic variant asthma (CVA) and atopic cough (AC).

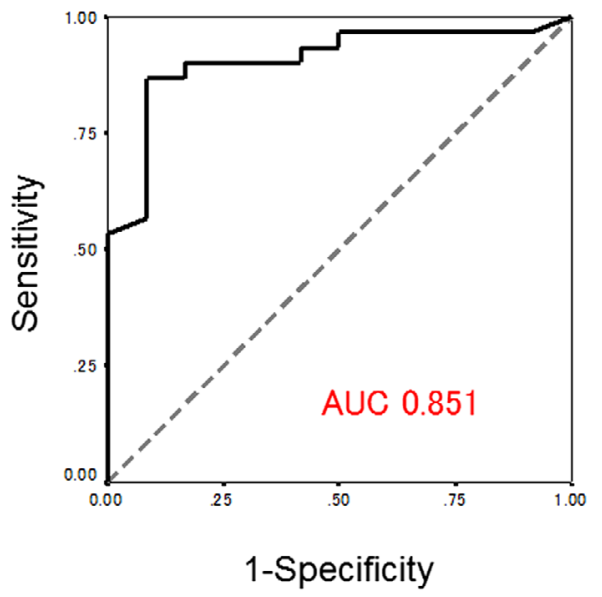

Figure 5. The receiver operating characteristic (ROC) curve for predicting the efficacy of bronchodilator therapy (BDT) in patients with chronic nonproductive cough $(n=42)$, which can help make the differential diagnosis between chronic variant asthma (CVA) and atopic cough (AC).

fected by the modulatory effects of deep inspiration $(6,7)$. The VAS scores were not correlated with reversibility of the FEV $_{1}$ (Fig. 3b). The FEV 1 cannot be used to detect mild bronchial smooth muscle contractions due to the modulatory effects of deep inspiration (bronchoconstriction when bronchodilation is induced), which supports the finding that the parameters of PFTs, such as $\mathrm{FEV}_{1}$, are normal in patients with CVA (2). In addition, patients with CVA have mild BHR (2); however, a diagnosis cannot be made based on the presence of BHR. Irwin et al. (15) suggested that BHR results cannot be used to predict the efficacy of BDT in treating the cough, similar to our findings (Fig. 3d). Therefore, our results suggest that the reversibility of the $\mathrm{PEF}_{40}$ can be used to predict the efficacy of BDT in treating the cough, which can help to make a diagnosis of CVA. We recently demonstrated that CVA patients with mild bronchoconstric-
Table 2. Cutoff Values, Sensitivity and Specificity of the Percent Increase in the PEF $_{40}$ for Predicting the Efficacy of Bronchodilator Therapy (BDT) in Patients with Chronic Nonproductive Cough $(n=42)$

\begin{tabular}{lll}
\hline Cutoff value & Sensitivity & Specificity \\
$10 \%$ & 88 & 33 \\
$15 \%$ & 85 & 47 \\
$20 \%$ & 82 & 75 \\
$25 \%$ & 68 & 83 \\
$30 \%$ & 65 & 83 \\
\hline
\end{tabular}

tion cough frequently, a finding that is not observed in normal subjects. This suggests that a heightened cough response to bronchoconstriction is a fundamental feature of CVA (5).

We conducted a further analysis based on the final diagnosis of CVA and $\mathrm{AC}$ in order to determine if reversibility of the $\mathrm{PEF}_{40}$ could be used to distinguish between patients with CVA and patients with AC. Fig. 4 shows that the reversibility of the $\mathrm{PEF}_{40}$ in the patients with CVA was significantly higher than that observed in the patients with $\mathrm{AC}(\mathrm{p}<$ 0.01). The ROC curve was used to evaluate the diagnostic performance of the reversibility of the $\mathrm{PEF}_{40}$ for diagnosing CVA and AC. The best cutoff point was 20\% (AUC: 0.851, sensitivity: $82 \%$, specificity: $75 \%$ ) (Fig. 5). Similarly, the efficacy of BDT in treating the cough was significantly negatively correlated with the $\mathrm{C} 5$ value (Fig. $3 \mathrm{c}$ ). It has been reported that bronchoconstriction-triggered cough, which is relevant to CVA, occurs via A $\delta$-fibers, but not C-fibers (16). We previously reported that patients with CVA have normal C5 values (12), while patients with AC have low C5 values (12). Therefore, our results showed that patients with CVA exhibit a $>20 \%$ increase in the $\mathrm{PEF}_{40}$ following inhalation of SABA and have normal C5 values, while patients with AC exhibit a $<20 \%$ increase in the $\mathrm{PEF}_{40}$ following inhalation of SABA and have low C5 values.

The potential disadvantage of the $\mathrm{PEF}_{40}$ metric is that obtaining reproducible measurements is very difficult. Spirometry is widely used and reliable; however, it is complex and requires the full cooperation of the patient (17). Obtaining reproducible measurements of the $\mathrm{PEF}_{40}$ is more difficult than performing traditional spirometry because it is necessary to match the level of the tidal inspiratory volume, which is the beginning of the partial flow-volume curve. Future efforts should be made to make performing this procedure less difficult.

In conclusion, the reversibility of the $\mathrm{PEF}_{40}$ predicts the efficacy of BDT in treating chronic nonproductive cough. We believe that this parameter can be used to make a diagnosis based on the pathophysiological condition of the patient rather than making a diagnosis based on the therapeutic response in patients with chronic nonproductive cough.

The authors state that they have no Conflict of Interest (COI). 


\section{Acknowledgement}

We wish to thank the staff of the Physiological Function Laboratory at Kanazawa University Hospital for their valuable technical assistance in this study.

\section{References}

1. Fujimura M, Abo M, Ogawa $H$, et al. Importance of atopic cough, cough variant asthma and sinobronchial syndrome as causes of chronic cough in Hokuriku area of Japan. Respirology 10: 201207, 2005.

2. Corrao WM, Braman SS, lrwin RS. Chronic cough as the sole presenting manifestation of bronchial asthma. N Engl J Med 300: 633-637, 1979.

3. Kohno S, Ishida T, Uchida Y, et al; Committee for the Japanese Respiratory Society Guidelines for Management of Cough. The Japanese Respiratory Society guidelines for management of cough. Respirology 11: 135-186, 2006.

4. Pratter MR, Brightling CE, Boulet LP, Irwin RS. An empiric integrative approach to the management of cough: ACCP EvidenceBased Clinical Practice Guidelines. Chest 129: 222-231, 2006.

5. Ohkura N, Fujimura M, Nakade Y, Okazaki A, Katayama N. Heightened cough response to bronchoconstriction in cough variant asthma. Respirology 17: 964-968, 2012.

6. Fish JE, Ankin MG, Kelly JF, Peterman VI. Regulation of bronchomotor tone by lung inflation in asthmatic and nonasthmatic subjects. J Appl Physiol 50: 1079-1086, 1981.

7. Fujimura M, Kamio Y, Hashimoto T, Matsuda T. Log normal distribution of bronchial responsiveness to methacholine in normal young adults. Jpn J Physiol 43: 541-552, 1993.

8. American Thoracic Society. Standardization of spirometry. Eur Respir J 26: 319-338, 2005.
9. Ryan G. Standardization of inhalation provocation tests: influence of nebulizer output, particle size, and method of inhalation. J Allergy Clin Immunol 67: 156-161, 1981.

10. Fujimura M, Kasahara K, Yasui M, et al. Atopy in cough sensitivity to capsaicin and bronchial responsiveness in young females. Eur Respir J 11: 1060-1063, 1998.

11. Centor RM. Signal detectability: the use of ROC curves and their analyses. Med Decis Making 11: 102-106, 1991.

12. Fujimura M, Kamio Y, Hashimoto T, Matsuda T. Cough receptor sensitivity and bronchial responsiveness in patients with only chronic nonproductive cough: in view of effect of bronchodilator therapy. J Asthma 31: 463-472, 1994.

13. Fujimura M, Ogawa $H$, Yasui M, Matsuda T. Eosinophilic tracheobronchitis and airway cough hypersensitivity in chronic nonproductive cough. Clin Exp Allergy 30: 41-47, 2000.

14. Fujimura M, Ogawa H, Nishizawa $Y$, Nishi K. Comparison of atopic cough with cough variant asthma: is atopic cough a precursor of asthma? Thorax 58: 14-18, 2003.

15. Irwin RS, French CT, Smyrnios NA, Curley FJ. Interpretation of positive results of a methacholine inhalation challenge and 1 week of inhaled bronchodilator use in diagnosing and treating coughvariant asthma. Arch Intern Med 157: 1981-1987, 1997.

16. Ohkura N, Fujimura M, Hara J, Ohsawa M, Kamei J, Nakao S. Bronchoconstriction-triggered cough in conscious guinea pigs. Exp Lung Res 35: 296-306, 2009.

17. Beydon N, Davis SD, Lombardi E, et al; American Thoracic Society/European Respiratory Society Working Group on Infant and Young Children Pulmonary Function Testing. An official American Thoracic Society/European Respiratory Society statement: pulmonary function testing in preschool children. Am J Respir Crit Care Med 175: 1304-1345, 2007.

(C) 2013 The Japanese Society of Internal Medicine http://www.naika.or.jp/imonline/index.html 